\title{
Napier Grass Rumen Degradability in Sacco in Goats (Capra hircus aegagrus) Supplemented with Different Sources and Amount of Dietary Fats
}

\author{
Niel L. Ningal \\ College of Agriculture and Food Science, University of the Philippines Los Baños, Los Baños, Laguna, Philippines \\ Email: nielningal.qualipeak@gmail.com
}

How to cite this paper: Ningal, N.L. (2020) Napier Grass Rumen Degradability in Sacco in Goats (Capra hircus aegagrus) Supplemented with Different Sources and Amount of Dietary Fats. Journal of Agricultural Chemistry and Environment, 9 , 177-194.

https://doi.org/10.4236/jacen.2020.93015

Received: April 30, 2020

Accepted: August 25, 2020

Published: August 28, 2020

Copyright $\odot 2020$ by author(s) and Scientific Research Publishing Inc. This work is licensed under the Creative Commons Attribution International License (CC BY 4.0). http://creativecommons.org/licenses/by/4.0/

\section{Open Access}

\begin{abstract}
The study aimed to explore the potential of dietary fats supplementation on the overall goat performance. Three (3) mature rumen-cannulated goats weighting $27.33 \pm 1.53 \mathrm{~kg}$ housed in individual elevated metabolism stalls with customized fecal and urine collection tools with treatments replicated three times over time following the Complete Randomized Design (CRD). Animals were randomly selected on different dietary treatment at different cycle. For each cycle, animals were provided with $30 \%$ concentrate on the morning based on feed requirements $\{3 \%$ of their body weight (BW) dry matter (DM) basis $\}$ of the animals. Ad libitum feeding of Napier grass will follow thereafter. Clean drinking water were made available all the times in the respective animal watering troughs. The rumen-cannulated goats were supplemented with different levels of two dietary fats (VCO and Lard) with dietary treatment combinations as follows, Control and VCO and Lard at 3\% \& $5 \%$. Degradability of dry matter (DM), crude protein (CP), neutral detergent fiber (NDF) and acid detergent fiber (ADF) were collected sequentially in every cycle of the study. There were seven (7) days lag period in every cycle for the animals to return to each natural state. On the 8th day of every cycle, animals were given different dietary treatment. Sequential insertion of nylon bag was done on the 15th to 16th day ( 7 days after treatment). The results showed that degradability of the dry matter (DM) was noticed degraded exponentially on the first twelve hours of incubation and slower down in the next few hours until 48 hours. Crude protein, acid and neutral detergent fiber showed breakdown of components was observed in the first 48 hours of incubation. No significant difference $(P>0.05)$ among treatment means was observed in all parameters gathered. This implies that mature female goat diet
\end{abstract}


cannot be influenced by dietary fats from two different sources (VCO and Lard) at $3 \%$ to $5 \%$ supplementation. Based on the study conducted, dietary fats supplementation on goats such as VCO and lard given at the maximum level of $5 \%$ level did not influence the nutrient degradability of Napier grass in the rumen until it reaches at 48 hours of incubation. Supplementing ruminant diets with dietary fat in goats could increase the energy density of the animal's diet without adverse effect on rumen degradability. This simple, easy, and basic technique could also be applied to other animal species in pursuit of finding ways to formulate indigenous feedstuff materials that have potential nutritive values. Given the limitations such as the climatic and environmental constraints, this particular study would somehow serve as benchmark in conducting related researches in optimizing the conditions with respect to animal nutrition and feedstuff utilization. Thus, this study was done to augment productivity and to provide new opportunities for achieving enhanced growth performance in a way that alleviates poverty, improves food security and nutrition and promotes sustainable use of natural resources.

\section{Keywords}

Dietary Fats, Detergent Fiber Degradability, Complete Randomize Design, Napier Grass, VCO, Lard, Los Baños, Laguna, Philippines

\section{Introduction}

The rumen ecology is basically a fermentation vat that inhabits a huge amount of various microbes [1] [2]. Microbes in the reticulorumen include bacteria, protozoa, fungi, archaea and viruses. The United States Environmental Protection Agency (USEPA) [3] reported that during enteric fermentation in ruminants, methane is produced, the second most important greenhouse gas (GHG) emitted by livestock. The most appropriate technique in the ruminant production nowadays was to understand the rumen ecosystem and determine how to improved and attain the symbiotic relationship of the animals and the rumen microorganisms [4] [5] [6] [7], thus, to improve the digestion efficiency of the rumen microorganism for various feedstuffs.

As a popular tool for studying rumen digestion, degradability and ecology, the nylon bag (in sacco) technique [8] [9] [10] was used. The nylon-bag technique has become more widely used and it is now being recommended as a means for evaluating tropical livestock feeds. However, little work has been done on the practical application of the technique to the evaluation of feeding systems. The use of degradation characteristics as a means of formulating ration combinations for ruminants becomes an aide or guide especially for those nutritionists.

Several researchers employing the nylon-bag technique [11] [12] [13] to study ruminant digestion use a specific basal diet so as to minimize any variations between animals and different trial periods within animals. However, while the results gained do indicate relatively dry-matter digestibility (DMD) of forages, 
they do not represent natural conditions where the animals are free-ranging and there is variation in basal diets and hence in DMD efficiencies.

\section{Materials and Methods}

\subsection{Care \& Management of Animals}

The study was conducted at the Metabolism Laboratory of the Institute of Animal and Dairy Sciences Cluster (ADSC), University of the Philippines, Los Baños, College, Laguna, Philippines.

Three (3) mature (rumen-cannulated goats) weighting $27.33 \pm 1.53 \mathrm{~kg}$ were housed in individual elevated metabolism stalls provided with $30 \%$ concentrate in the morning based on feed requirements (3\% of their body weight (BW) dry matter (DM) basis) of the animals. Ad libitum feeding of Napier grass follows thereafter. Clean drinking water were made available all the time in the respective animal watering troughs.

Degradability on DM, CP, NDF and ADF were collected sequentially in every cycle of the study. There were seven (7) days lag period in every cycle for the animals to return to each natural state. On the 8th day of every cycle, animals were given different dietary treatment. Sequential insertion of nylon bag was done on the 15th to 16th day (7 days after treatment).

\subsection{Research Design and Lay-Out}

Three mature goats surgically fitted with rumen cannula were used. The experimental animals were in good body condition prior to and throughout the duration of the study. Complete Randomized Design (CRD) was used to evaluate the effect of different dietary treatments. Five dietary treatments were used in the study with dietary treatment combinations as follows.

\subsubsection{Treatment Combinations}

The rumen-cannulated goats were supplemented with different levels of two dietary fat sources with dietary treatment combinations as follows (Table 1):

Treatment 1-CONTROL

Treatment $2 \%$ - 3\% Virgin Coconut Oil (VCO)

Treatment 3\% - 5\% Virgin Coconut Oil (VCO)

Treatment $4 \%$ - 3\% Lard

Treatment 5\% - 5\% Lard

Animal were randomly selected on different dietary treatment at different cycle. For each cycle, animals were provided with Napier grass ad libitum in the

Table 1. Treatment assignment of goats for the entire duration of the study.

\begin{tabular}{cccccc}
\hline Treatment & Initial & $1^{\text {st }}$ Cycle & $2^{\text {nd }}$ Cycle & $3^{\text {rd }}$ Cycle & $4^{\text {th }}$ Cycle \\
\hline Animal 1 & T3 & T2 & T5 & T4 & T1 \\
Animal 2 & T2 & T3 & T4 & T1 & T5 \\
Animal 3 & T5 & T4 & T3 & T1 & T2 \\
\hline
\end{tabular}


morning and concentrate (30\%) in the afternoon. Free access to clean potable water was made available at all time. All data were collected sequentially in every cycle of the study. There were 7 days lag period in every cycle for the animals to return to each natural state.

On the 8th day of every cycle animals were given different dietary treatment. Sequential insertion of nylon bag was done on the 15th to16th day (7 days after treatment).

\subsubsection{Laboratory Analysis}

Evaluation of Napier grass rumen degradability in sacco in supplemented with different sources and amount of dietary fats were done through different biochemical analysis of different parameters gathered such as.

\subsubsection{Experimental Treatment}

A total of 48 nylon bags measuring $17 \times 10 \mathrm{~cm}$ each were prepared with 16 bags each animal. All bags containing around $5 \mathrm{~g}$ grounded Napier grass sample were incubated into the rumen following sequential elimination at $0,3,6,9,12,24,36$ and 48th hours.

After incubation, the bags were immediately placed in cold water to stop fermentation, and to remove the feed particles adhering to the bags. Then, it was rinsed under running water for about 20 minutes or until the wash water is cleaned. (A good guide to the sample and bag being clean is when the water from a slowly running tap will run out of the bag as quickly as it enters.) The bags are then dried to a constant weight at $60^{\circ} \mathrm{C}-70^{\circ} \mathrm{C}$ for 24 hours. The washed samples were placed in a desiccator (for 20 - 30 minutes) kept at room temperature. Percent digestion of feedstuff and digestion kinetic parameters is then calculated using the exponential equation:

$$
\begin{gathered}
D=a+b(1-e-c t) \\
e-c t=(a+b-D) / b
\end{gathered}
$$

where: $D=$ Degradation (\% degradation), $a=$ intercept (soluble fractions), $b=$ potential degradable fraction, $c=$ degradation rate of fraction $b$, and $e=$ natural logarithm [12].

Representative samples were analyzed for dry matter following the AOAC method; Crude protein using Kjeldahl analysis based on AOAC [14] procedure, Neutral detergent fiber (NDF) and Acid detergent fiber (ADF) analysis were done following the Van Soest and Wine [15] procedure. This was done on the 15th to 16th day of every consecutive cycle.

Data were further subject to NEWAY software analysis to generate data on degradation and regression fit curve.

\section{Result and Discussion}

\subsection{DM Degradability}

The dry matter degradability of Napier grass after incubation for each incuba- 
tion period $(0,3,6,9,12,24,36$ and 48 hours) in goats fed with varying levels of dietary fats (coco oil and lard) in the concentrate was presented (Figure 1) showed that degradability of the dry matter (DM) content of the Napier was found to be $72.30 \%$ at 48 hrs of incubation. The $68 \%$ potentially degradable fraction has a rate of degradation (disappearance) at $49 \%$.

After 48 hours of incubation, control got the highest degradation with $49.170 \%$ followed by treatment given with VCO (5\%), Lard (5\%), Lard (3\%), and VCO (3\%) with $48.77,48.14,40.38$, and 39.47 percent, respectively.

It was also observed that the percentage degradability (\% loss) of DM was noticed exponentially on the first twelve hours of incubation and slower down on the next few hours until 48 hours. Result ranges from 39\% - 49\% dry matter degradability however, no significant difference $(\mathrm{P}>0.05)$ among treatment means was observed on dry matter degradability. This may imply that rumen microorganism did not utilize the dry matter content of Napier grass efficiently. However, it may also indicate that extending the incubation in the rumen makes the sample totally degraded by rumen microbes [1] [2].

Napier grass dry matter disappearance in the rumen at various incubation time in goat fed different dietary fats (Table 2) showed that different treatment

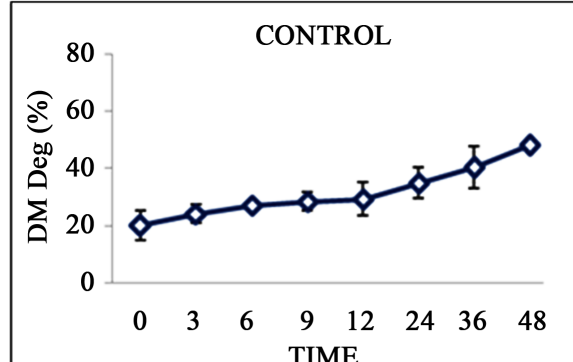

TIME
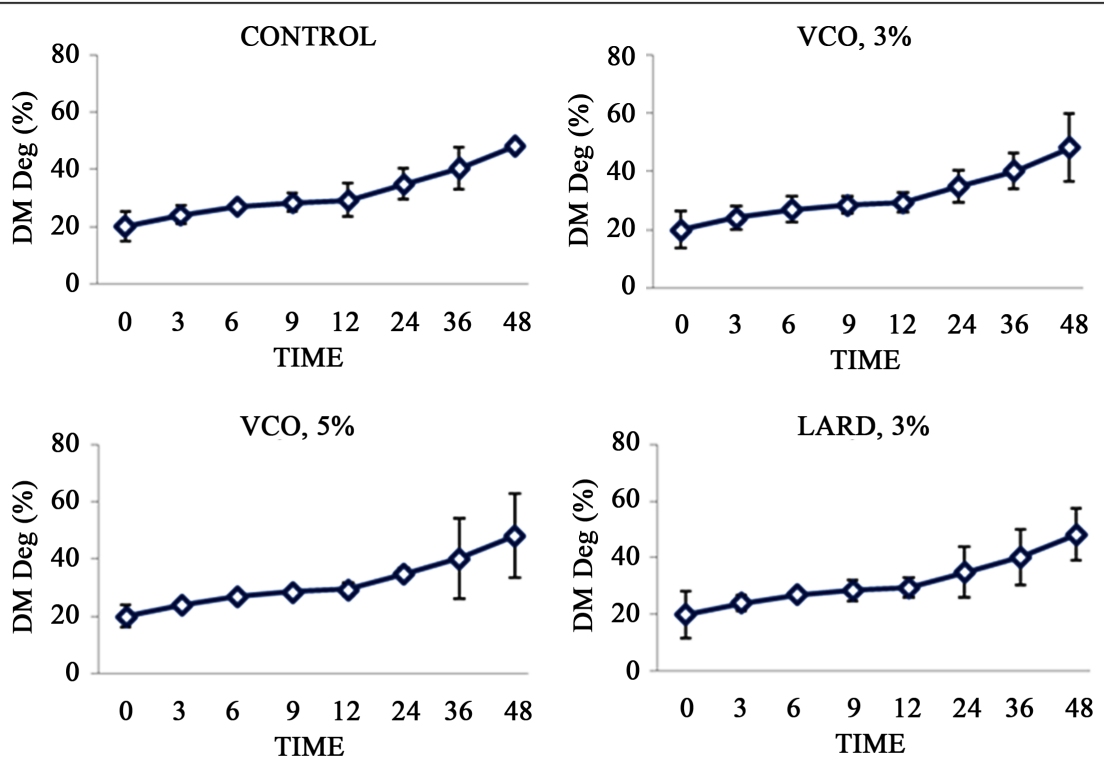

LARD, 5\%

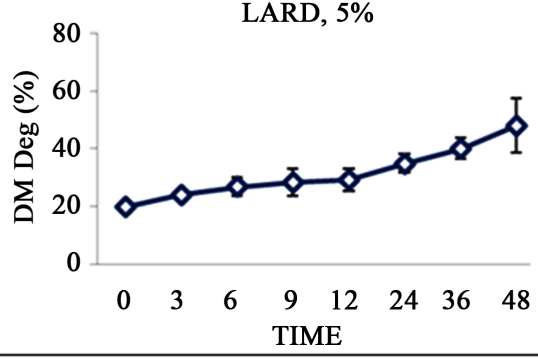

Figure 1. Mean \pm SD of dry matter degradability of mature goats in sacco supplemented with different levels and sources of dietary fats. 
Table 2. Mean \pm SD dry matter disappearance in the goat's rumen of Napier grass at various incubation times in goat.

\begin{tabular}{|c|c|c|c|c|c|}
\hline \multirow{2}{*}{ Treatment } & \multirow{2}{*}{$a$} & \multirow{2}{*}{$a+b$} & \multicolumn{3}{|c|}{$\mathrm{ED}$ (outflow rate/hour) ${ }^{1}$} \\
\hline & & & 0.02 & 0.05 & 0.08 \\
\hline CONTROL & $17.2 \pm 5.31$ & $52.7 \pm 21.2069 .9 \pm 26.500 .031 \pm 0.03$ & $42.0 \pm 1.04$ & $32.0 \pm 1.70$ & $28.1 \pm 1.25$ \\
\hline VCO, $3 \%$ & $18.3 \pm 6.38$ & $47.1 \pm 33.1965 .4 \pm 37.410 .060 \pm 0.09$ & $35.8 \pm 9.75$ & $28.6 \pm 4.87$ & $26.0 \pm 4.02$ \\
\hline $\mathrm{VCO}, 5 \%$ & $20.7 \pm 3.82$ & $40.3 \pm 31.3761 .0 \pm 33.810 .036 \pm 0.03$ & $45.8 \pm 17.38$ & $34.0 \pm 4.47$ & $30.0 \pm 1.99$ \\
\hline LARD, 3\% & $20.8 \pm 8.32$ & $24.5 \pm 8.6245 .3 \pm 16.260 .122 \pm 0.16$ & $36.6 \pm 8.98$ & $31.7 \pm 5.65$ & $29.4 \pm 4.59$ \\
\hline LARD, 5\% & $20.0 \pm 2.01$ & $44.0 \pm 31.5264 .0 \pm 32.120 .049 \pm 0.06$ & $43.3 \pm 10.60$ & $32.9 \pm 0.99$ & $29.4 \pm 1.11$ \\
\hline
\end{tabular}

soluble fractions (a) ranges from $17.2 \%-20.8 \%$ with the highest readily soluble fraction from treatment supplemented with lard (3\%) and the lowest was coming from the control. Readily soluble fractions were high on fat supplemented compare from control. However, the soluble fraction of Napier grass DM in rumen of female mature goat was not significantly $(\mathrm{P}>0.05)$ differ with dietary fat supplementation.

The insoluble but potentially fermentable fraction $(b)$ of Napier grass DM decreased with fat supplementation. The insoluble but potentially fermentable fraction of Napier grass on rumen of goat with fat supplementation on Control, VCO (3\%), Lard (5\%), VCO (5\%), Lard (3\%) were 52.7\%, 47.1\%, 44.0\%, 40.3\% and $24.5 \%$, respectively.

Adding of dietary fat on the concentrate decreases the potential fermentable fraction of Napier grass. This could be due to the decrease of microbial population present in the rumen during fat supplementation. Addition of fat will result to depression in fiber digestion in the rumen [16] [17]. Also, saturated fatty acids such as coconut oil have been shown to have a toxic effect on protozoa and methanogens [16] [18]. In similar study feeding 3.5\% and 7\% coconut oil reduced ciliate protozoa to $[1.0(105 \mathrm{ml} / \mathrm{li})$ and $0.3(105 \mathrm{ml} / \mathrm{li})]$, respectively, compared to no oil supplementation [1.7 (105 ml/li)] [18].

Potentially digestible fraction $(\mathrm{a}+\mathrm{b})$ on the goat rumen at various incubation time supplemented with different dietary fats on the concentrate ranges from $45.0 \%-69.9 \%$ with a highest potentially digestible fraction from control groups while the lowest was coming from Lard (3\%) (Figure 2).

Degradation rate of DM of Napier grass in the rumen showed that Control got the lowest degradation rate of 0.031 followed by VCO (5\%), Lard (5\%), VCO (3\%), and Lard (3\%) of 0.036, 0.049, 0.06 and 0.122 , respectively. No significant difference $(\mathrm{P}>0.05)$ across treatments at different incubation period in terms of DM degradation rate of Napier in the rumen of goat supplemented with different dietary fats was observed. 


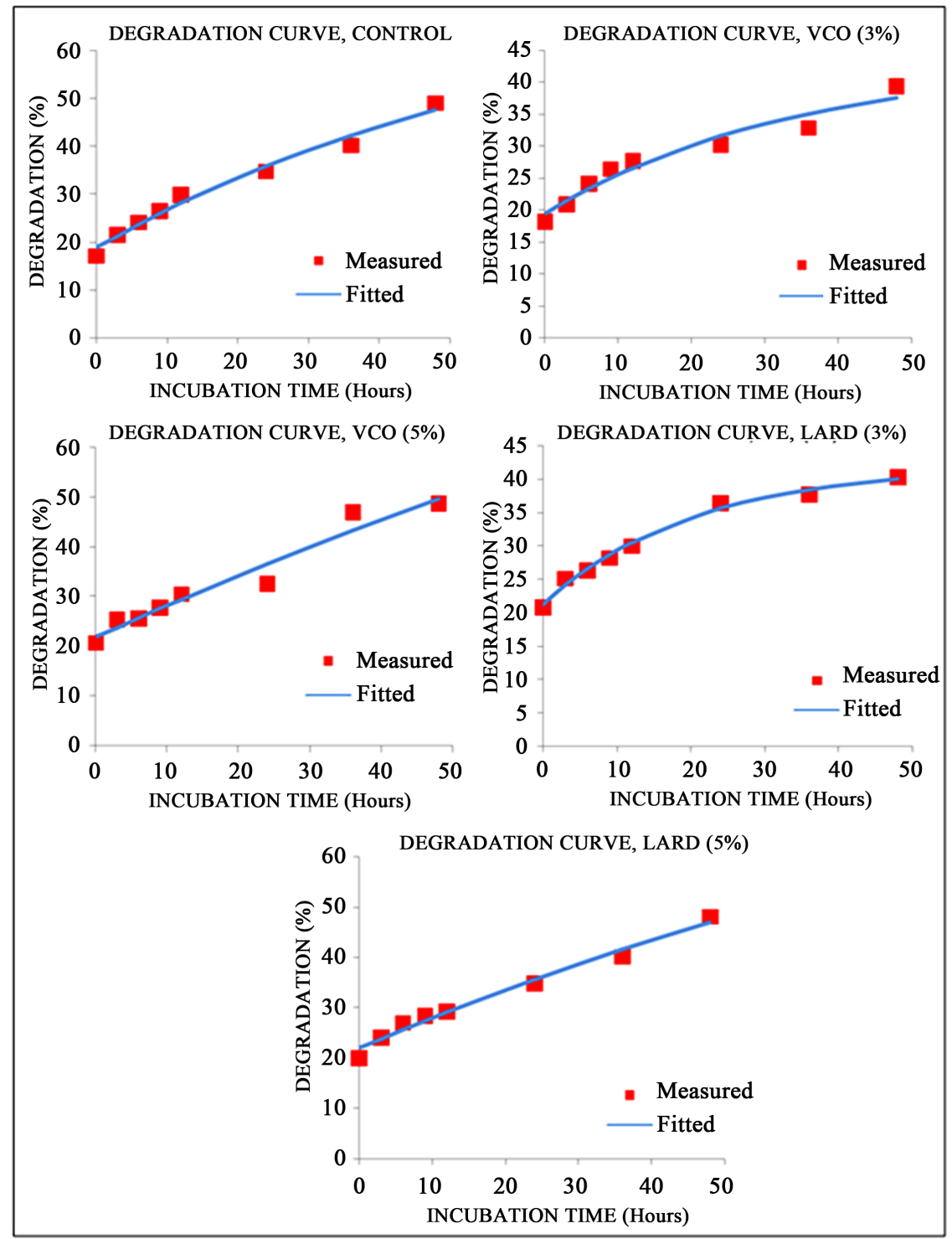

Figure 2. Dry matter degradation curve in mature goats.

Effective degradability at $0.02,0.05$ and 0.08 outflow rate/hour was tabulated to evaluate the effect of different dietary fats on the degradability of Napier grass at specific outflow rate/hour. Data showed that goat fed with VCO (5\%) got the highest effective degradability followed in decreasing order of treatments, Lard (5\%), Control, Lard (3\%) and VCO (3\%). Despite of difference on outflow rate/hour at $0.02,0.05$ and 0.08 , no significant difference $(P>0.05)$ were observed on among treatment means on outflow rate/hour.

Goat supplemented with $5 \%$ fats got the better effective degradability of Napier grass whereas the $3 \%$ supplemented group got the meager result. Despite variation on different treatments given, no significant difference $(P>0.05)$ observed across treatments at different incubation period. This implies further that adding dietary fat on the concentrate as high as $5 \%$ does not influence the goat's degradability performance of Napier grass. 


\subsection{Crude Protein Degradability}

Crude protein degradability of Napier grass after incubation period $(0 \mathrm{~h}, 3 \mathrm{~h}, 6 \mathrm{~h}$, $9 \mathrm{~h}, 12 \mathrm{~h}, 24 \mathrm{~h}, 36 \mathrm{~h}$ and $48 \mathrm{~h}$ ) in goats fed with varying levels of dietary fats (coco oil and lard) presented (Figure 3 ) showed that after 48 hours of incubation, VCO (5\%) got the highest crude protein degradation with $7.110 \%$ followed by control group, Lard (5\%), Lard (3\%), VCO (3\%) with 7.0, 6.4, 5.6 and 5.1 percent, respectively. However, the differences between treatments failed to satisfy the $\mathrm{P}<0.05$, hence all treatment means for crude protein degradability were comparable.

The crude protein (CP) degradability resulted to $60.98 \%$ of the $11.66 \% \mathrm{CP}$ content of the Napier grass, a $7.11 \%$ breakdown of protein components after 48 hrs of incubation. Although more than $17.36 \%$ was observed between the lowest to highest $\mathrm{CP}$ degradability after 48 hours, no significant difference $(\mathrm{P}>0.05)$ among treatment means was observed., This implies that supplementing 3 to $5 \%$ dietary fats from two different sources (VCO and Lard) in ruminant diet do not influence the crude protein degradability of mature female goats.

The result deviate on the study of Henry [19] and Dawson [20] that crude protein is $97 \%$ digestible those aided rumen microbes for reproduction and good

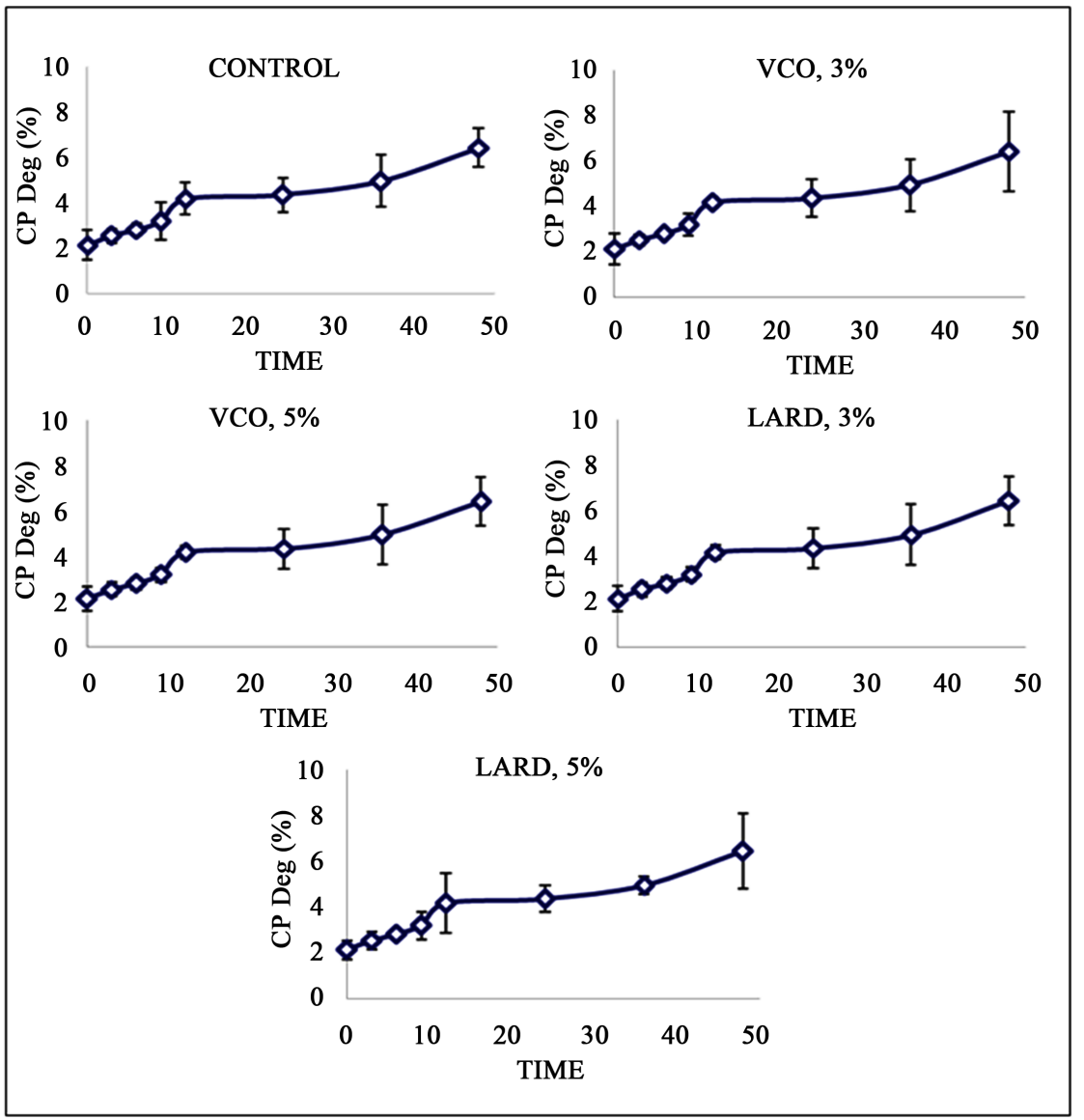

Figure 3. Mean \pm SD of crude protein degradability mature goats in sacco supplemented with different levels and sources of dietary fats. 
digestion. The deviation of the result could be due to limited number of exposed time of forage material to the microbes in the rumen. Ørskov and McDonald [12] stated that potential degradability of roughages degraded in the rumen for about 70 hours.

Napier grass dry matter disappearance in the rumen at various incubation time in goat fed different dietary fats (Table 3) showed that different treatment soluble fractions (a) ranges from $15.967 \%-19.367 \%$ with the highest readily soluble fraction from NGC + CO (5\%) and the lowest was coming from the control group. Readily soluble fractions were apparently higher on fat supplemented compare from control group. However, the soluble fraction of Napier grass crude protein in rumen of goat was not significant influenced dietary fat supplementation. The insoluble but potentially fermentable fraction (b) of Napier grass CP decreased with fat supplementation except for VCO (5\%) treatment with $80.6 \%$ potential fermentable fraction followed by control with $69.1 \%$, followed by Lard (5\%) of $51.5 \%$, followed by VCO (3\%) of $45.4 \%$ and the lowest insoluble but potentially fermentable fraction was coming from Lard (3\%) of $39.4 \%$.

Potentially digestible fraction $(\mathrm{a}+\mathrm{b})$ on the goat rumen at various incubation time supplemented with different dietary fats on the concentrate ranges from 57.933 to $100.000 \%$ with a highest potentially digestible fraction from NGC + CO (5\%) while the lowest was coming from NGC + L (3\%).

Results also revealed that there is no significant difference $(P>0.05)$ across treatments at different incubation period in terms of $\mathrm{CP}$ potentially digestible fraction. No interaction effect on fat source, level and block was observed. The result emphasized that adding of fats (coco oil and lard) as high as 5\% do not influence the changes in potentially digestible fraction of CP of Napier grass in the rumen.

Degradation rate of $\mathrm{CP}$ of Napier grass in the rumen showed that $3 \%$ fat supplementation group got the highest degradation rate of 0.063 followed by VCO (5\%), control, Lard (5\%), of $0.029 \%, 0.020 \%$, and $0.003 \%$, respectively. No

Table 3. Mean \pm SD CP disappearance in the goat's rumen of Napier grass at various incubation times in goat.

\begin{tabular}{|c|c|c|c|c|}
\hline \multirow{2}{*}{ Treatment } & \multirow{2}{*}{$a$} & \multirow{2}{*}{$a+b$} & \multicolumn{2}{|c|}{ ED (outflow rate/hour) ${ }^{1}$} \\
\hline & & & 0.05 & 0.08 \\
\hline CONTROL & $16.0 \pm 5.5269 .1 \pm 24.67$ & $85.1 \pm 25.8080 .020 \pm 0.03$ & $52.5 \pm 10.8133 .8 \pm 2.19$ & $28.0 \pm 2.40$ \\
\hline $\mathrm{VCO}, 3 \%$ & $16.6 \pm 5.8345 .4 \pm 31.97$ & $62.0 \pm 37.0890 .063 \pm 0.08$ & $38.3 \pm 12.4729 .3 \pm 5.83$ & $25.9 \pm 4.01$ \\
\hline $\mathrm{VCO}, 5 \%$ & $19.4 \pm 4.7480 .6 \pm 4.74$ & $100.0 \pm 0.000 \quad 0.003 \pm 0.00$ & $58.9 \pm 9.5136 .5 \pm 3.35$ & $30.5 \pm 2.23$ \\
\hline LARD, $3 \%$ & $18.6 \pm 6.1539 .4 \pm 9.70$ & $57.9 \pm 15.6180 .063 \pm 0.05$ & $45.1 \pm 7.0636 .9 \pm 3.16$ & $32.7 \pm 2.0$ \\
\hline LARD, $5 \%$ & $18.2 \pm 3.4751 .5 \pm 26.02$ & $69.7 \pm 26.9350 .029 \pm 0.02$ & $48.9 \pm 11.6835 .1 \pm 2.98$ & $30.1 \pm 1.8$ \\
\hline
\end{tabular}


significant difference $(\mathrm{P}>0.05)$ across treatments at different incubation period in terms of CP degradation rate of Napier grass in the goat rumen supplemented with different dietary fats on the concentrate was been observed although there were variations on the resulting data, statistics showed insignificant. Data revealed that no interaction effect on between fat source, level and replication. The result further emphasized that adding of fats (coco oil and lard) as high as 5\% do not influenced the changes in $\mathrm{CP}$ degradation rate of Napier grass in the rumen (Figure 4).

Effective degradability at $0.02,0.05$ and 0.08 outflow rate/hour was tabulated to evaluate the effect of different dietary fats on the degradability of Napier grass at specific outflow rate/hour. Data showed that goat fed with VCO (5\%) got the highest effective degradability followed in decreasing order of treatments, Control, Lard (5\%), Lard (3\%), and VCO (3\%).

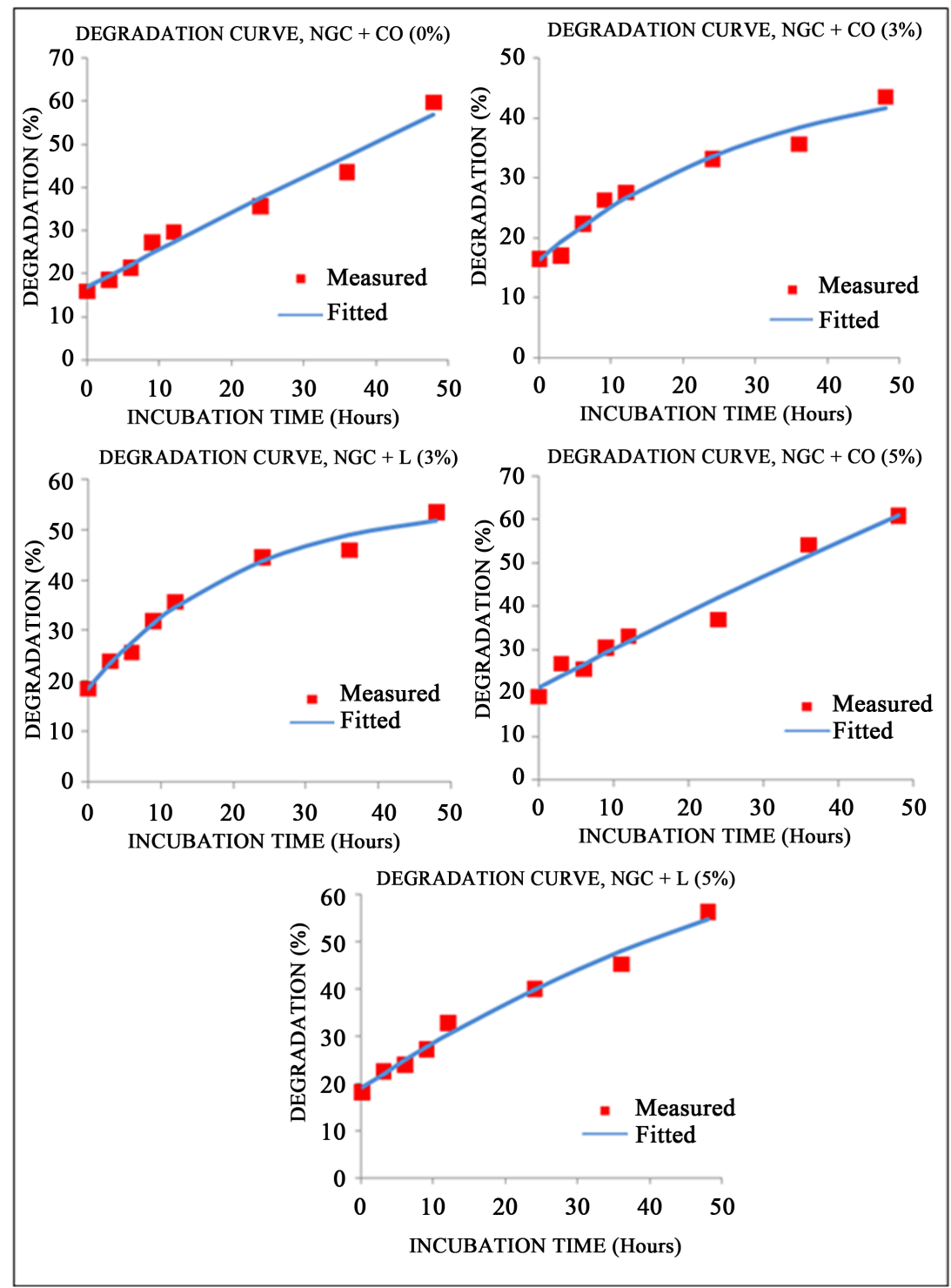

Figure 4. Crude protein degradation curve in mature goats. 
Goat supplemented with $5 \%$ fats got the better effective degradability of Napier grass whereas the $3 \%$ supplemented group got the lowest result. Despite of variation on different treatments given, no significant difference $(P>0.05)$ observed across treatments at different incubation period. This implies further that adding dietary fat on the concentrate as high as $5 \%$ do not influence the crude protein degradability performance of Napier grass on goat.

\subsection{Neutral Detergent Fiber Degradability}

Neutral detergent fiber degradability of Napier grass after incubation period (0 h, $3 \mathrm{~h}, 6 \mathrm{~h}, 9 \mathrm{~h}, 12 \mathrm{~h}, 24 \mathrm{~h}, 36 \mathrm{~h}$ and $48 \mathrm{~h}$ ) in goats fed with varying levels of dietary fats (coco oil and lard) (Figure 5) showed that after 48 hours of incubation, Control got the highest neutral detergent fiber degradation with $18.43 \%$ and the lowest was coming from Lard (3\%) of 11.84\% (Figure 6).

The neutral detergent fiber degradability (NDF) resulted to $27.03 \%$ of the $68.21 \%$ of NDF content of Napier grass, a $18.43 \%$ breakdown of neutral detergent fiber components after 48 hours. Although there were $11.42 \%$ difference from the highest to the lowest NDF degradability after 48 hours, no significant

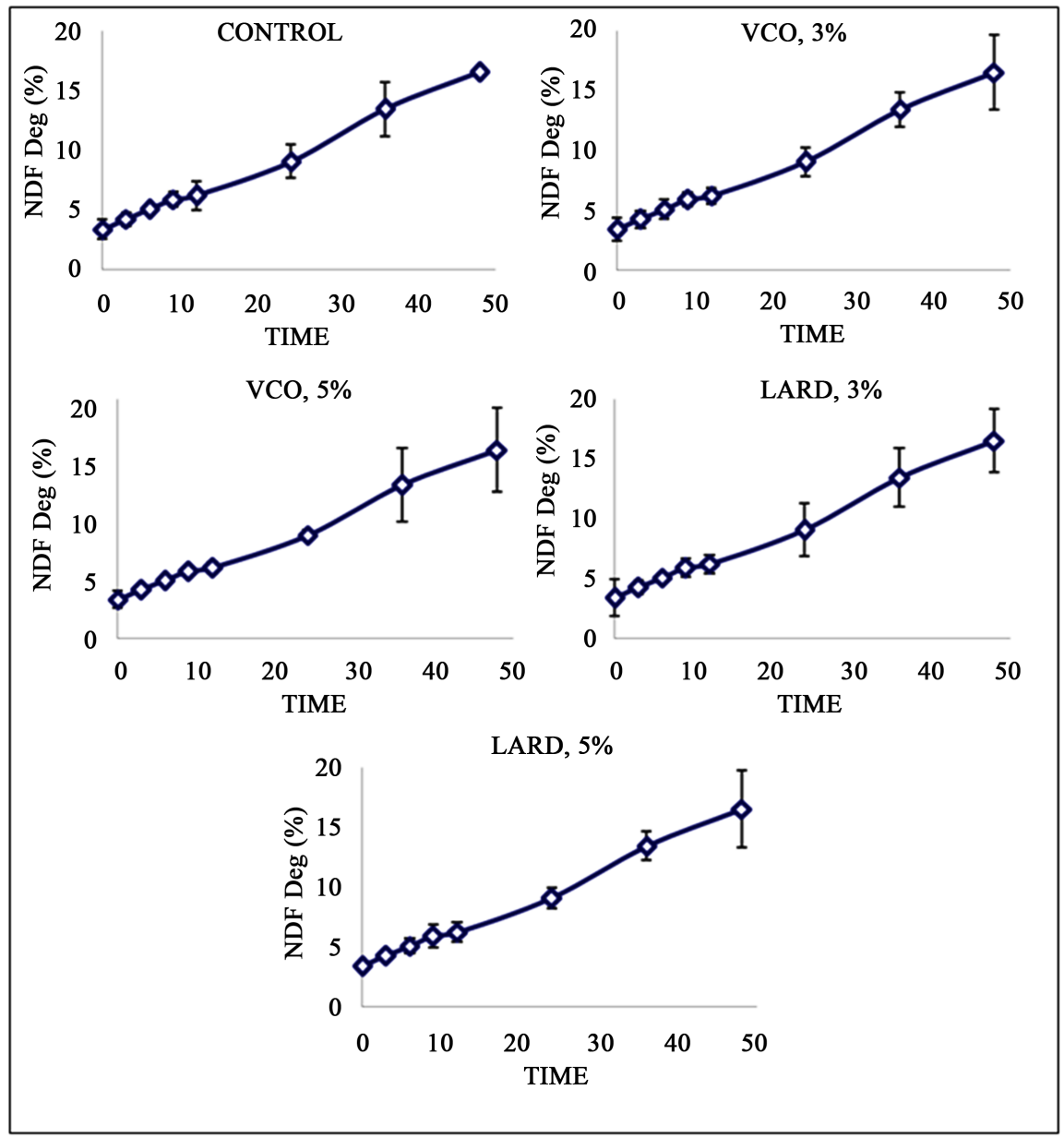

Figure 5. Mean \pm SD of neutral detergent fiber degradability mature goats in sacco supplemented with different levels and sources of dietary fats. 


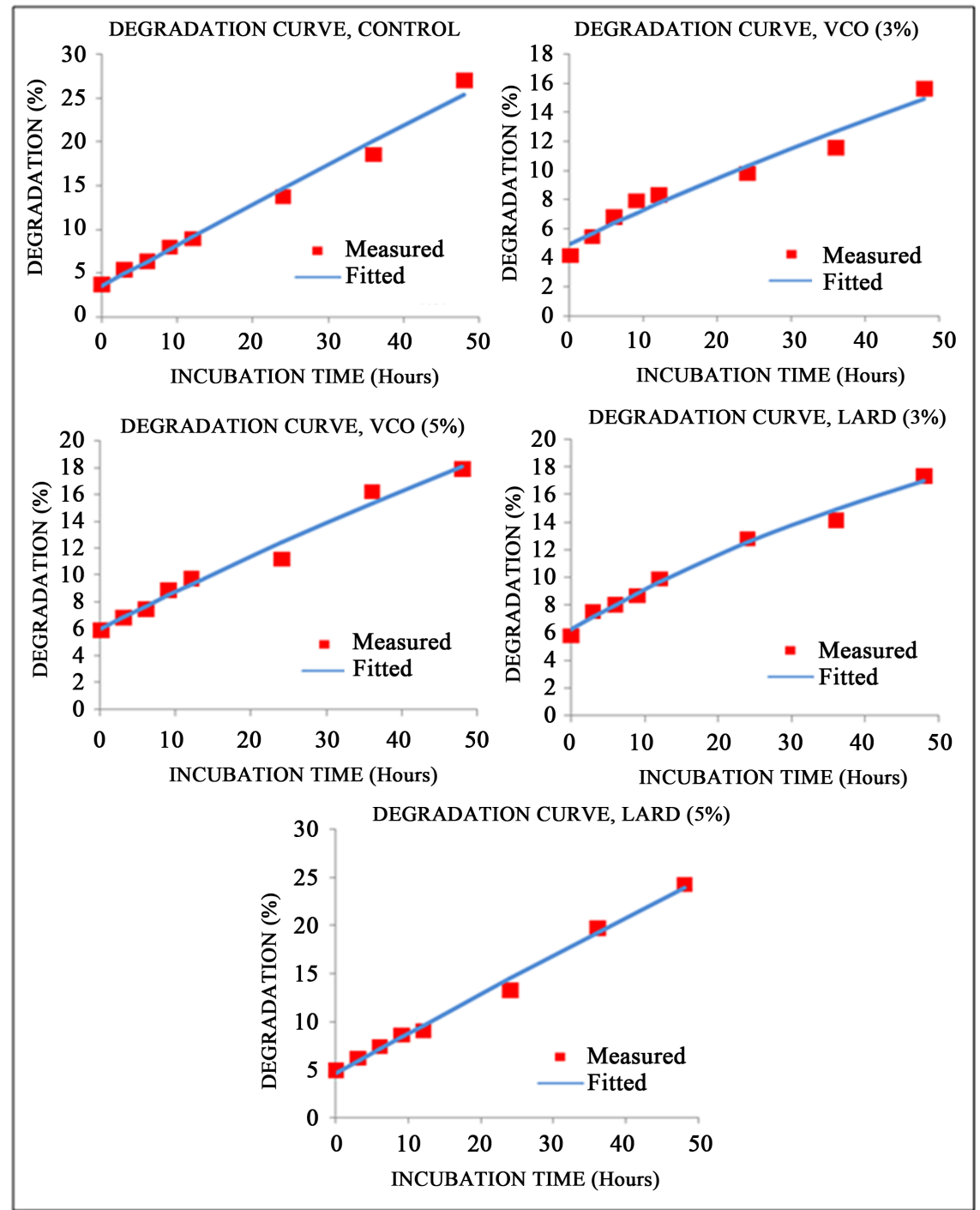

Figure 6. Neutral detergent fiber degradation curve in mature goats.

difference $(\mathrm{P}>0.05)$ among treatment means was observed., This implies that mature female goat diet cannot be influenced by dietary fats from two different sources (VCO and Lard) at 3\% to 5\% supplementation. This shows that rumen microorganism partly utilized the NDF content of Napier grass efficiently. On the other hand, extending the incubation in the rumen can increase the degradability of Napier grass by rumen microbes [1] [2].

Napier grass neutral detergent fiber disappearance in the rumen at various incubation time in goat fed different dietary fats on the concentrate (Table 4) showed that different treatment NDF soluble fractions (a) range from 3.8\% $5.9 \%$ with the highest readily soluble fraction from VCO (5\%) and the lowest was coming from the control group. Readily soluble fractions were high on fat supplemented compare from the control group. However, the soluble fraction of Napier grass crude protein in rumen of goat was not significant $(P>0.05)$ influenced dietary fat supplementation. 
Table 4. Mean \pm SD NDF disappearance in the goat's rumen of Napier grass at various incubation times in goat.

\begin{tabular}{|c|c|c|c|c|c|c|}
\hline \multirow{2}{*}{ Treatment } & \multirow{2}{*}{ a } & \multirow{2}{*}{$b$} & $a+b$ & \multicolumn{3}{|c|}{ ED (outflow rate/hour) ${ }^{1}$} \\
\hline & & & $a+v$ & 0.02 & 0.05 & 0.08 \\
\hline CONTROL & $3.8 \pm 1.16$ & $96.2 \pm 1.16$ & $100.0 \pm 0.000 .003 \pm 0.00$ & $24.8 \pm 1.22$ & $12.7 \pm 0.85$ & $9.4 \pm 0.50$ \\
\hline VCO, $3 \%$ & $4.1 \pm 1.46$ & $65.3 \pm 51.19$ & $69.5 \pm 51.680 .028 \pm 0.05$ & $14.0 \pm 4.84$ & $9.3 \pm 1.64$ & $7.8 \pm 1.10$ \\
\hline $\mathrm{VCO}, 5 \%$ & $5.9 \pm 1.06$ & $38.1 \pm 47.81$ & $44.0 \pm 48.500 .142 \pm 0.21$ & $16.3 \pm 6.35$ & $11.2 \pm 2.00$ & $9.5 \pm 0.67$ \\
\hline LARD, 3\% & $5.8 \pm 2.34$ & $31.7 \pm 21.42$ & $37.5 \pm 23.600 .030 \pm 0.04$ & $15.5 \pm 4.72$ & $11.1 \pm 2.20$ & $9.6 \pm 1.65$ \\
\hline LARD, $5 \%$ & $4.9 \pm 0.50$ & $79.8 \pm 22.49$ & $84.8 \pm 22.870 .004 \pm 0.00$ & $22.9 \pm 4.22$ & $12.8 \pm 0.81$ & $9.9 \pm 0.10$ \\
\hline
\end{tabular}

The NDF insoluble but potentially fermentable fraction $(b)$ of Napier grass on the was high on the treatment without supplementation of $96.2 \%$ followed by Lard (5\%) of $79.8 \%$, followed by VCO (3\%) of $65.3 \%$, followed by VCO (5\%) with $38.1 \%$ and the lowest insoluble but potentially fermentable fraction was coming from Lard (3\%) of 31.7\%. Adding of dietary fat on the concentrate lowers the potential fermentable fraction of Napier grass NDF in the rumen. Despite $64.5 \%$ difference, result showed no significant difference $(P>0.05)$ among treatment means was observed.

Neutral detergent fiber potentially digestible fraction $(a+b)$ of Napier on the goat rumen at various incubation time supplemented with different dietary fats on the concentrate ranges from $37.5 \%$ to $100 \%$ with a highest potentially digestible fraction from the control while the lowest was coming from Lard (3\%).

Results also revealed that there is no significant difference $(P>0.05)$ across treatments at different incubation period in terms of NDF potentially digestible fraction.

Degradation rate of NDF of Napier grass in the rumen showed that VCO (5\%) got the highest degradation rate of $14.2 \%$ followed by Lard (3\%), VCO (3\%), Lard (5\%) and control with $3 \%, 2.8 \%, 0.4 \%$ and $0.3 \%$, respectively. NDF degradation rate of Napier grass showed no significant difference $(P>0.05)$ across treatments at different incubation period. Although there were variations on the resulting data, statistics showed insignificant. The result further emphasized that adding of fats (coco oil and lard) as high as $5 \%$ do not influence the changes in NDF degradation rate of Napier grass in the rumen.

Effective degradability at $0.02,0.05$ and 0.08 outflow rate/hour was tabulated to evaluate the effect of different dietary fats on the degradability of Napier grass at specific outflow rate/hour. Data showed that control got the highest effective degradability while VCO (3\%) showed the lowest. Comparing the supplemented group, goat supplemented with $5 \%$ fats got the better effective degradability compared from the $3 \%$ supplemented group but despite variation on different treatments given, no significant difference $(P>0.05)$ observed across treatments at different incubation period. This implies further that adding dietary fat on the 
concentrate as high as $5 \%$ do not influence the NDF degradability performance of Napier grass on goat.

\subsection{Acid Detergent Fiber Degradability}

Neutral detergent fiber degradability of Napier grass after incubation period (0 h, $3 \mathrm{~h}, 6 \mathrm{~h}, 9 \mathrm{~h}, 12 \mathrm{~h}, 24 \mathrm{~h}, 36 \mathrm{~h}$ and $48 \mathrm{~h}$ ) in goats fed with varying levels of dietary fats (coco oil and lard) on the concentrate was presented (Figure 7) shows that after 48 hours of incubation. The acid detergent fiber degradability (NDF) resulted to $31.71 \%$ of the $38.04 \%$ of NDF content of Napier grass, a $12.06 \%$ breakdown of acid detergent fiber components after 48 hours. Although ADF degradability ranges from $18.3 \%-31.7 \%$ with $13.4 \%$ difference from the highest to the lowest ADF degradability after 48 hours, no significant difference ( $\mathrm{P}>$ 0.05) among treatment means was observed., This implies that mature female goat diet cannot be influenced by dietary fats from two different sources (VCO and Lard) at $3 \%$ to $5 \%$ supplementation. This shows that rumen microorganism was partly utilized the ADF content of Napier grass efficiently. On the other hand, extending the incubation in the rumen can increase the degradability of Napier grass by rumen microbes [1] [2].

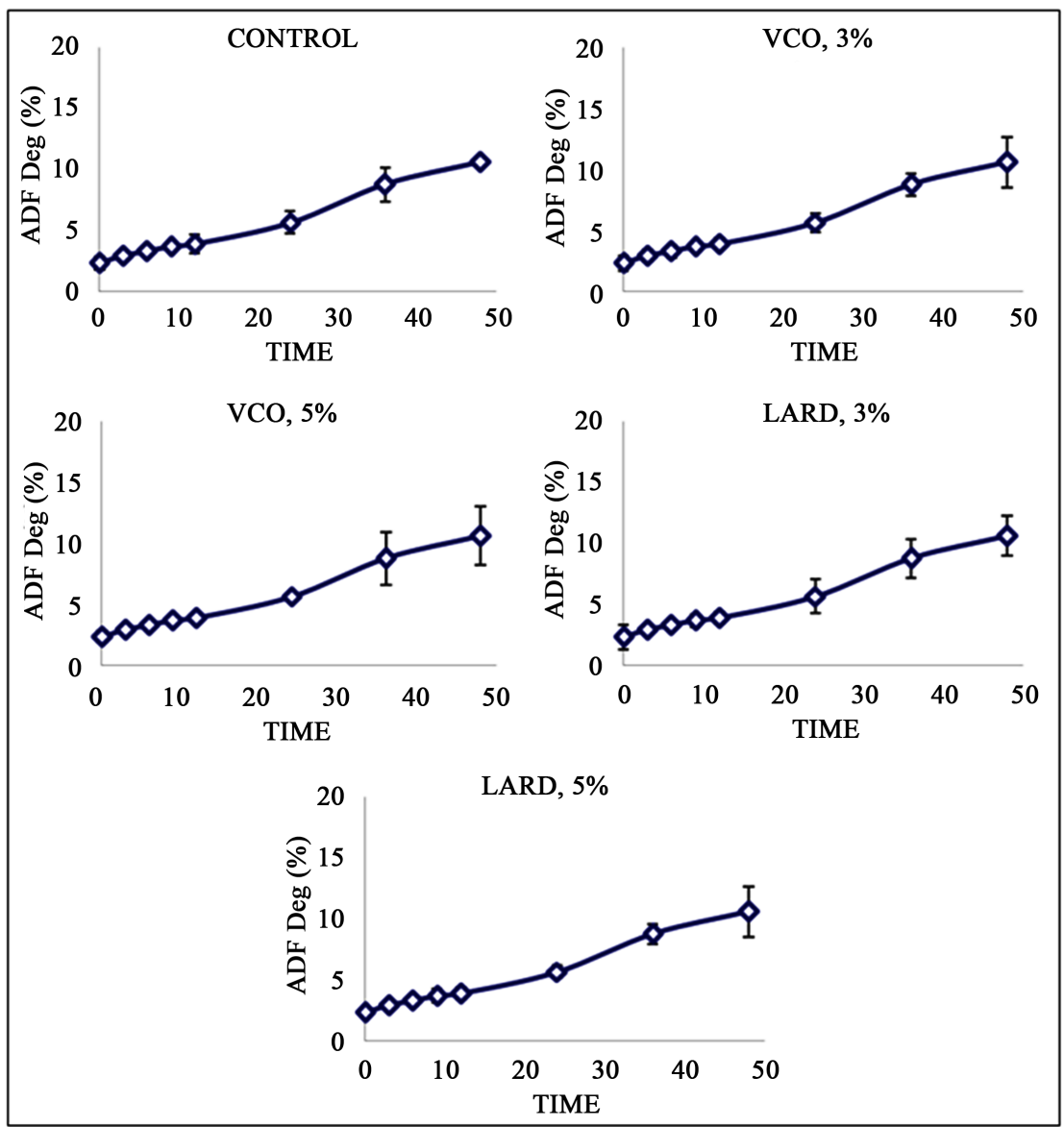

Figure 7. Mean $\pm \mathrm{SD}$ of acid detergent fiber degradability mature goats in sacco supplemented with different levels and sources of dietary fats. 
Results show that there is no significant difference $(\mathrm{P}>0.05)$ across treatments at incubation period at $0,6,9,12$, and 24 hours of incubation. On the other hand, significant differences $(\mathrm{P}<0.05)$ were observed at $36 \mathrm{~h}$ and $48 \mathrm{~h}$ of incubation. No differences were observed between control and treatments supplemented with 5\% dietary fats while control and 3\% dietary supplementation showed significant difference (Figure 8).

Napier grass ADF disappearance in the rumen at various incubation time in goat fed different dietary fats on the concentrate (Table 5) showed that different treatment $\mathrm{ADF}$ soluble fractions (a) range from $4.3 \%$ - $6.8 \%$ with the highest readily soluble fraction from VCO (5\%) and the lowest was coming from the control. Readily soluble fractions were high on fat supplemented compare from

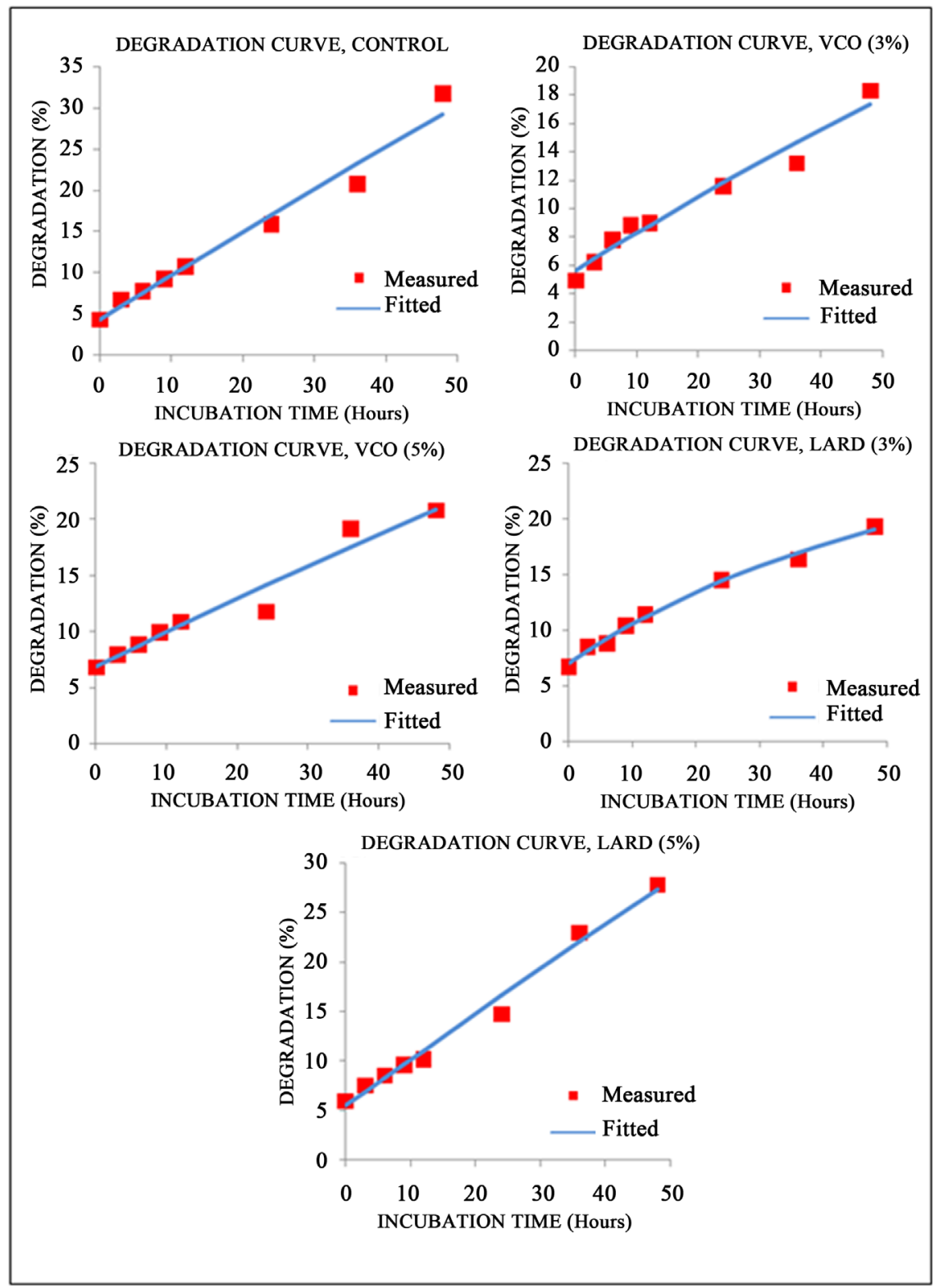

Figure 8. Acid detergent fiber degradation curve in mature goats. 
Table 5. Mean \pm SD ADF disappearance in the goat's rumen of Napier grass at various incubation times in goat.

\begin{tabular}{|c|c|c|c|c|c|c|c|}
\hline \multirow{2}{*}{ Treatment } & \multirow{2}{*}{$a$} & \multirow{2}{*}{$b$} & \multirow{2}{*}{$a+b$} & \multirow{2}{*}{$c$} & \multicolumn{3}{|c|}{ ED (outflow rate/hour) ${ }^{1}$} \\
\hline & & & & & 0.02 & 0.05 & 0.08 \\
\hline CONTROL & $4.3 \pm 1.37$ & $95.7 \pm 1.37$ & $100.0 \pm 0.00$ & $0.003 \pm 0.003$ & $28.7 \pm 1.47$ & $14.8 \pm 0.95$ & $11.0 \pm 0.60$ \\
\hline $\mathrm{VCO}, 3 \%$ & $4.9 \pm 1.72$ & $65.8 \pm 50.02$ & $70.8 \pm 50.63$ & $0.018 \pm 0.026$ & $16.4 \pm 5.55$ & $10.6 \pm 1.97$ & $8.9 \pm 1.40$ \\
\hline $\mathrm{VCO}, 5 \%$ & $6.8 \pm 1.27$ & $41.1 \pm 44.29$ & $47.9 \pm 45.12$ & $0.017 \pm 0.013$ & $19.2 \pm 7.28$ & $12.8 \pm 1.92$ & $10.8 \pm 0.89$ \\
\hline LARD, 3\% & $6.7 \pm 2.69$ & $25.9 \pm 14.64$ & $32.7 \pm 17.26$ & $0.038 \pm 0.046$ & $17.1 \pm 5.05$ & $12.6 \pm 2.38$ & $11.0 \pm 1.79$ \\
\hline LARD, 5\% & $6.0 \pm 0.60$ & $89.2 \pm 7.71$ & $95.2 \pm 8.26$ & $0.003 \pm 0.002$ & $26.6 \pm 4.38$ & $14.7 \pm 0.91$ & $11.4 \pm 0.12$ \\
\hline
\end{tabular}

control group. However, the ADF soluble fraction of Napier grass in rumen of goat was not significant $(\mathrm{P}>0.05)$ influenced dietary fat supplementation.

The ADF insoluble but potentially fermentable fraction $(b)$ of Napier grass decreases upon increasing the amount of coconut oil on the concentrate while inversely result on lard supplemented group.

Acid detergent fiber potentially digestible fraction $(a+b)$ of Napier on the goat rumen at various incubation time supplemented with different dietary fats on the concentrate showed control as the highest with $100.0 \%$ followed by Lard (5\%), VCO (3\%), VCO (5\%) and Lard (3\%) with 95.2, 70.8, 47.9 and 32.7 percent, respectively. Results also revealed that a $67.3 \%$ difference showed no significant difference $(\mathrm{P}>0.05)$ among treatments means at different incubation period.

Degradation rate of ADF of Napier grass in the rumen showed that Lard (3\%) got the highest degradation rate while control to be the lowest group. No significant difference $(\mathrm{P}>0.05)$ across treatments at different incubation period. Effective degradability at $0.02,0.05$ and 0.08 outflow rate/hour on the other hand showed that control got the highest effective degradability while VCO (3\%) showed the lowest. Comparing the supplemented group, 5\% dietary fats supplementation got the better effective degradability compared to the $3 \%$ supplemented group. Despite variation on different treatments given, no significant difference $(\mathrm{P}>0.05)$ observed among treatment means at different incubation period. This implies further that adding dietary fat on the concentrate as high as $5 \%$ do not influence the ADF effective degradability performance of Napier grass on goat.

\section{Conclusion}

Based on the study conducted, dietary fats supplementation on goats such as VCO and lard given at the maximum level of 5\% level did not influence the nutrient degradability of Napier grass in the rumen until it reaches at 48 hours of incubation. Supplementing ruminant diets with dietary fat in goats could in- 
crease the energy density of the animal's diet without adverse effect on rumen degradability.

\section{Acknowledgements}

The Filipino people and its administering agencies such as DOST/PCAARRD/SEI, through the Accelerated Science \& Technology Human Resource Development Program for the graduate scholarship;

To my advisory committee for their guidance, advices and recommendations and to Dr. Antonio A. Rayos, for conducting rumenotomy on the experimental animals.

To all staff of Animal Nutrition Laboratory, University of the Philippines Los Baños, for their kind assistance during this study.

To my family for the inspiration, encouragement and financial support to finish this study.

To all my professors in UPLB, for the valuable knowledge you've shared and for pushing me to work harder and strive for excellence.

To the UPLB Graduate School staff, for their guidance and kind help.

\section{Conflicts of Interest}

The author declares no conflicts of interest regarding the publication of this paper.

\section{References}

[1] Bach, A. (2006) New Concepts in Protein Nutrition of Ruminants. Institució Catalana de Recerca i Estudis Avançats (ICREA) and Institut de Recerca I Tecnologia Agroalimentàries, IRTA-Unitat de Remugants, Barcelona.

[2] Stern, M.D. (2006) New Concepts in Protein Nutrition of Ruminants. Department of Animal Science, University of Minnesota, St. Paul.

[3] United States Environmental Protection Agency (EPA) (2014). http://www.epa.gov/climatechange/ghgemission

[4] Chanjula, P., Wanapat, M., Wachirapakora, C., Uriyapongson, S. and Rowlinson, P. (2003) Ruminal Degradability of Tropical Feeds and Their Potential Use in Ruminant Diets. Asian-Australasian Journal of Animal Sciences, 16, 211-216. https://doi.org/10.5713/ajas.2003.211

[5] Chen, C.-S., Wang, S.-M. and Hsu, J.-T. (2006) Factors Affecting In Vitro True Digestibility of Napier Grass. Asian-Australasian Journal of Animal Sciences, 19, 507-513. https://doi.org/10.5713/ajas.2006.507

[6] Madigan, M.T. and Martinko, J.M. (2006) Biology of Microorganisms. 11th Edition, Pearson Prentice Hall, Upper Saddle River, 163-637.

[7] Moran, J. (2005) How the Rumen Works. In: Moran, J., Ed., Tropical Dairy Farming. Feeding Management for Small Holder Dairy Farmers in the Humid Tropics, Landlinks Press, Melbourne, 41-50. https://doi.org/10.1071/9780643093133

[8] Fina, L.R., Teresa, G.W. and Bartley, E.E. (1958) An Artificial Rumen Technique for Studying Rumen Digestion In Vivo. Journal of Animal Science, 17, 667. https://doi.org/10.2527/jas1958.173667x 
[9] Quin, J.I., Van Der Wath, J.G. and Hyburth, S. (1938) Studies on the Alimentary Canal of Merino Sheep in South Africa. 4. Description of Experimental Technique. Onderstepoort Journal of Veterinary Science and Animal Industry, 11, 341.

[10] Ørskov, E.R., Hovell, F.D. and Mould, F. (1980) The Use of the Nylon Bag Technique for the Evaluation of Feedstuffs. Tropical Animal Production, 5, 195-213.

[11] Chen, X. and Orskov, E. (2004) Research on Urinary Excretion of Purine Derivatives in Ruminants: Past, Present and Future. In: Makkar, H.P.S. and Chen, X.B., Eds., Estimation of Microbial Protein Supply in Ruminants Using Urinary Purine Derivative, Springer, Berlin, 180-210. https://doi.org/10.1007/978-1-4020-2844-1_21

[12] Orskov, E.R. and McDonald, I. (1979) The Estimation of Protein Degradability in the Rumen from Incubation Measurements Weighed According to Rate of Passage. The Journal of Agricultural Science, 92, 499. https://doi.org/10.1017/S0021859600063048

[13] Van Dyne, G.M. (1962) Micro-Methods for Nutritive Evaluation of Range Forages. Journal of Range Management, 14, 303-314. https://doi.org/10.2307/3894761

[14] Association of Analytical Chemist (AOAC) (1995) Official Methods of Analysis of AOAC International. 16th Edition, Association of Official Analytical Chemists, Arlington.

[15] Van Soest, P.J. and Wine, R.H. (1967) Use of Detergents in the Analysis of Fibrous Feeds, IV. Determination of Plant Cell-Wall Constituents. Journal of Association of Official Analytical Chemists, 50, 50-55. https://doi.org/10.1093/jaoac/50.1.50

[16] Dong, Y., Bae, H.D., Mcallister, T.A., Mathison, G.W. and Cheng, K.-J. (1997) Lipid-Induced Depression of Methane Production and Digestibility in the Artificial Rumen System (RUSITEC). Canadian Journal of Animal Science, 77, 269-278. https://doi.org/10.4141/A96-078

[17] Mathison, G.W., Okine, E.K., Mcallister, T.A., Dong, Y., Galbraith, J. and Dmytruk, O.I.N. (1998) Reducing Methane Emissions from Ruminant Animals. Journal of Applied Animal Research, 14, 1-28. https://doi.org/10.1080/09712119.1998.9706212

[18] Machmüller, A. and Kreuzer, M. (1999) Methane Suppression by Coconut Oil and Associated Effects on Nutrient and Energy Balance in Sheep. Canadian Journal of Animal Science, 79, 65-72. https://doi.org/10.4141/A98-079

[19] Henry, M. (2013) Why Lard Is Healthier than You Think. https://www.thestar.com/life/health_wellness/nutrition/2013/05/14/why_lards_heal thier_than_you_think.html

[20] Dawson, R.M. (1953) Use Lard. North Dakota Agricultural College and U.S. Department of Agriculture Cooperating. 